doi:10.12662/2359-618xregea.v8i1.p42-54.2019

\title{
ARTIGOS
}

\section{HIDROVIAS DO BRASIL: UM ESTUDO DE INTELIGÊNCIA DE MARKETING}

\author{
HIDROVIAS DO BRASIL: A MARKETING INTELLI- \\ GENCE STUDY
}

\section{HIDROVIAS DEL BRASIL: UN ESTUDIO DE INTELI- GENCIA DE MARKETING}

\section{RESUMO}

O presente trabalho se apresenta sob a modalidade de pesquisa exploratória qualitativa. Como método, foi utilizado o estudo de caso. $\mathrm{O}$ fenômeno estudado é a atividade de inteligência de marketing sob a perspectiva da empresa HBSA. Como resultado de estudo, verificou-se que as atividades de inteligência de marketing ocorrem, informalmente, nas diversas unidades de negócios. Observou-se que uma série de ações relativas a estudos de cenários e oportunidades de mercado é realizada na empresa, configurando a presença de atividades de inteligência de marketing, as quais auxiliam a estruturação de decisões de mercado.

Palavras-chave: Inteligência. Marketing. Marketing Logística.

\footnotetext{
Luciano Augusto Toledo Doutor em Administração pela FEA/USP. Professor na Universidade Presbiteriana Mackenzie. São Paulo - SP-BR. E-mail: <Luciano.toledo@, mackenzie.br>.
}

Felix Hugo Aguero Diaz Leon Doutor em Administração pela Universidade Presbiteriana Mackenzie. Professor da Universidade Presbiteriana Mackenzie. São Paulo - SP-BR E-mail:<felix.leon@mackenzie. $b r>$.

\begin{abstract}
The present work is presented under the modality of qualitative exploratory research and as method it was used the method of the case study. The phenomenon studied is the activity of marketing intelligence from the perspective of the HBSA company. As a result of the study, it was found that marketing intelligence activities occur informally in the various business units. It was observed that a series of actions regarding scenario studies and market opportunities are carried out in the company, characterizing the presence of marketing intelligence activities, activities that help market decisions structuring.
\end{abstract}

Keywords: Marketing intelligence. Marketing. Marketing Logistics.

\section{RESUMEN}

El presente trabajo se presenta bajo la modalidad de pesquisa exploratoria cualitativa y como método fue utilizado el estudio de caso. El fenómeno estudiado es la actividad de inteligencia de marketing bajo la 
perspectiva de la empresa HBSA. Como resultado del estudio se verificó que las actividades de inteligencia de marketing ocurren informalmente en las diversas unidades de negocios. Fue observado que una serie de acciones relativas a estudios de escenario y oportunidades de mercado son realizadas en la empresa, configurando la presencia de actividades de inteligencia de marketing. Actividades que ayudan en la estructuración de decisiones de mercado.

Palabras-clave: Inteligencia Marketing. Marketing. Logística.

\section{INTRODUÇÃO}

Cada vez mais, em um mundo globalizado, conquistar e manter clientes representa algo fundamental para qualquer negócio. A realidade da globalização provocou profundas mudanças nas empresas. Elementos como qualidade e competitividade deixaram de ser apenas um diferencial entre as organizações para se tornarem fator de sobrevivência no mercado global. As empresas estão tentando encontrar maneiras de melhorar sua flexibilidade e capacidade de resposta e, por sua vez, a competitividade, alterando sua estratégia de operações, métodos e tecnologias (GUNASEKARAN, 2004). Colocar o produto certo, no local certo, na hora certa, pelo menor preço é a grande meta a ser alcançada (BARBOSA; TOLEDO; ZILBER, 2016; VALDÉS, 2003).

A logística é a atividade da administração responsável pelo planejamento, pela organização e pelo controle de todo o fluxo de mercadorias e informação, desde a fonte fornecedora até o consumo. Logística é muito mais do que visão de depósito, palete, caminhão etc., ela se preocupa com a qualidade, os custos, os prazos e os ciclos dos serviços prestados no atendimento a clientes. Esses fatores fazem que a logística esteja em constante evolução e revolução de conceitos e técnicas, integrados ao ambiente de marketing; ou seja, o resultado de um bom trabalho logístico, reduzindo custos e aumentando a eficiência, certamente será lucro (FLYNN; HUO; ZHAO, 2014; WAGNER; EGGERT, 2016). O gerenciamento da ca- deia de suprimentos engloba vários processos que são suportados por mecanismos de coordenação e integração que são estratégias de longo prazo que proporcionam vantagem competitiva por meio da eficiência geral da cadeia de suprimentos (PRAJOGO et al., 2018).

Atualmente, as empresas que se mantêm à frente são aquelas que conseguem aumentar a taxa de inovação, lançar produtos e serviços mais rapidamente, atender à demanda com tempos de espera menores e conquistar maior confiabilidade. A procura de vantagem competitiva tem-se tornado uma preocupação de todas as empresas atentas às realidades do mercado (GUMMESSON, 2014).

A HBSA - Hidrovias do Brasil é uma empresa nascida a partir de uma startup, fundada em 2010. Ela desenvolve soluções logísticas integradas na América Latina com foco no aproveitamento do transporte hidroviário, por meio de projetos inovadores e competitivos.

Constituída pelo fundo de infraestrutura do Pátria Investimentos, a Hidrovias do Brasil conta ainda com participação de outros fundos, como o canadense AIMCO; o Temasek, fundo soberano de Cingapura; o IFC - braço financeiro do Banco Mundial; e o BNDESPar, gestor de participações em empresas detidas pelo BNDES; entre outros sócios também representados pelo Pátria Infraestrutura. Desenvolvendo projetos customizados em toda a América Latina, a atuação da companhia abrange, atualmente, duas operações principais: Corredor Logístico Sul e Corredor Logístico Norte.

Para o desenvolvimento desses projetos, a inteligência de marketing fornece os subsídios necessários para a prática de estratégias mais assertivas. Assim, justifica-se um trabalho acadêmico que tem por problema de pesquisa: compreender de que maneira a inteligência de marketing é empregada para o desenvolvimento de estratégias de empresa do setor de Logística com a finalidade de ampliar a sua eficácia? Este estudo examina o papel da Inteligência de Marketing como direcionadora da configuração das estratégias da empresa HBSA. Com essa finalidade, analisou-se a Inteligência de Marketing da Empresa de Logística HBSA, empregando-se o método do estudo de caso (exploratório e qualitativo). 


\section{REFERENCIAL TEÓRICO}

\subsection{MARKETING ESTRATÉGICO}

A missão de qualquer negócio é fornecer valor ao cliente, sem abrir mão do lucro. Em uma economia extremamente competitiva, com compradores cada vez mais racionais diante de uma abundância de opções, uma empresa somente pode vencer ao ajustar o processo de entrega de valor e selecionar, proporcionar e comunicar um valor superior (KOTLER; KELLER, 2011). Seguindo essa lógica, observa-se que o Marketing Estratégico se torna um assunto cada vez mais discutido dentro do mundo corporativo, uma vez que, com o aumento de concorrentes, tende a diminuir o espaço de mercado das empresas, (principalmente os novos entrantes) e, assim, uma estratégia para identificar possíveis oportunidades de negócio e uma segmentação pode ser a solução.

O marketing estratégico apoia-se na análise das necessidades dos indivíduos e das organizações. $\mathrm{Na}$ óptica do marketing, o que o comprador procura não é o produto em si, mas o serviço ou a solução de um problema que é suposto o produto oferecer. A função do marketing estratégico é seguir a evolução do mercado de referência e identificar os diferentes produtos-mercado e segmentos atuais ou potenciais, na base da análise da diversidade de necessidades a satisfazer (LAMBIN, 2002).

O marketing estratégico consiste em atividades que permitem olhar o mercado e identificar grupos de interesse. Dentro desses grupos de interesse, tem-se o mercado alvo, o qual será de grande atratividade estratégica nas ações de marketing da empresa. Não obstante, após a identificação do mercado alvo, é necessária a definição das estratégias de posicionamento de mercado; ou seja, ao selecionar o mercado-alvo adequado, o foco será desenvolver o posicionamento do valor da oferta, que constitui a primeira etapa do marketing estratégico. A partir da definição do posicionamento, serão determinadas as estratégias e as ações relativas ao composto de marketing. A fórmula "segmentação, seleção de alvo (targeting), posicionamento" é a essência do marketing estratégico (AAKER; MCLOUGHLIN, 2010; BEEMER;
SHOOK, 1998; KERIN; PETERSON, 2009; ZENONE, 2007).

Um segmento de mercado consiste em um grande grupo que é identificado a partir de suas preferências, poder de compra, localização geográfica, atitudes de compra e hábitos de compra similares. Segmentação de marketing é um esforço para aumentar a precisão do marketing da empresa (AAKER; MCLOUGHLIN, 2010; BEEMER; SHOOK, 1998; KERIN; PETERSON, 2009; ZENONE, 2007).

Uma vez que a unidade de negócios tenha selecionado o valor, passa-se para a segunda etapa, a da entrega de valor. As especificações tangíveis do produto e dos serviços devem ser detalhadas; um preço-alvo deve ser estabelecido; o produto deve ser fabricado e distribuído. O desenvolvimento dos atributos específicos, dos preços e da distribuição acontece nessa etapa e é parte do marketing tático. A tarefa da terceira etapa é a comunicação do valor. Nessa etapa, acontece um marketing tático adicional na utilização da força de vendas, da promoção e de outras ferramentas adicionais para informar o mercado sobre o produto (AAKER; MCLOUGHLIN, 2010; BEEMER; SHOOK, 1998; KERIN; PETERSON, 2009; ZENONE, 2007).

Os aspectos-chave em marketing estratégico são: 1 - onde competir; 2 - como competir; e 3 - quando competir. O primeiro aspecto relaciona produtos e mercados e envolve questões sobre o escopo das atividades, como oferecer um produto ou serviço não diferenciado para um grupo de consumidores potenciais ou, talvez, a empresa deveria focar-se, especificamente, em um segmento escolhido. O aspecto sobre como competir é igualmente importante. A empresa atinge o sucesso somente se for capaz de atingir uma posição competitiva satisfatória (produto/mercado) no mercado escolhido (AAKER; MCLOUGHLIN, 2010; BEEMER; SHOOK, 1998; KERIN; PETERSON, 2009; ZENONE, 2007).

A consolidação do marketing estratégico na empresa permite: (1) fundamentar sua atividade em opções estratégicas sólidas e claramente definidas; (2) desenvolver sistemas de vigilância do ambiente e da análise da concorrência; (3) reforçar 
a capacidade de adaptação às mudanças do ambiente; (4) prever, regularmente, a renovação do portfólio de produtos-mercados (LAMBIN, 2002).

Para que o marketing estratégico consolide as estratégias de segmentação, identificação do mercado-alvo e posterior aplicação das estratégias de posicionamento, é fundamental conhecimento, o qual faz parte de dados obtidos do mercado e convertidos em informações parte da Inteligência de marketing.

\subsection{INTELIGÊNCIA DE MARKETING E SUAS CARACTERÍSTICAS}

A American Marketing Association (2018) define inteligência de mercado como o desenvolvimento de um sistema de coleta, processamento e disponibilização de dados e informações em formato que permite aos gestores de marketing e executivos trabalhar com mais eficiência. A inteligência de mercado integra marketing, vendas, serviços, por meio do mapeamento sistemático do mercado, promovendo a identificação de oportunidades e ameaças, necessitando, pois, da correta aplicação de inteligência no negócio da empresa (CALOF; WRIGHT, 2008; LAURINDO; MACUL, 2014; MILENA; PALACIOS, 2013; QUEIROZ, 2010; TOLEDO; MORAES; ZILBER, 2010; ZAPATA MENDIVELSO, 2015).

Não se pode negar que as estratégicas de marketing precisam basear-se em informações provenientes do mercado. Para isso, os profissionais de marketing fazem uso da inteligência competitiva para colher informações do mercado, transformar dados em conhecimentos e, dessa forma, conceber as melhores estratégias para a manutenção ou conquista de mercados novos ou já explorados (CALOF; WRIGHT, 2008; LAURINDO; MACUL, 2014; MILENA; PALACIOS, 2013; QUEIROZ, 2010; TOLEDO; MORAES; ZILBER, 2010; ZAPATA MENDIVELSO, 2015).

Sistema de Inteligência de Marketing é um conjunto de procedimentos e fontes, usado por administradores para obter informações diárias sobre os desenvolvimentos pertinentes no ambiente de marketing. Existem algumas características que podem ser implantadas na empresa, a fim de mo- dificar a inteligência de marketing e melhorá-la (CALOF; WRIGHT, 2008; LAURINDO; MACUL, 2014; MILENA; PALACIOS, 2013; QUEIROZ, 2010; TOLEDO; MORAES; ZILBER, 2010; ZAPATA MENDIVELSO, 2015). São elas:

a) capacitar e motivar a equipe de vendas: esses profissionais estão em contato direto com clientes e, com o mercado, adquirindo informações importantes sobre necessidades e exigências do consumidor, ações da concorrência, entre outros;

b) motivar distribuidores, revendedores, varejistas e demais intermediários, contribuindo para estreitar laços de relacionamento, mantendo um canal aberto para recebimento de informações;

c) adquirir, por meio de assinatura ou aquisição de relatórios de pesquisa, informações de empresas de pesquisa e consultoria;

d) analisar as informações, filtrando-as, separando as mais relevantes para que sejam repassadas aos administradores;

e) manter um canal aberto também com os colaboradores, independente de área de atuação. Essas pessoas, muitas vezes, possuem experiência em determinadas funções da empresa que podem ser úteis na resolução de um problema ou mesmo em um processo de inovação.

A Inteligência de Marketing consiste, basicamente, no entendimento das variáveis ambientais, assim como suas irmãs acadêmicas inteligência competitiva e inteligência de mercado. As diferenças entre elas são muito sutis e, praticamente, completam-se. A perspectiva de marketing, a qual implica a função troca em um ou mais mercados, acaba por presumir que as variáveis conduzem os agentes econômicos no processo de satisfação de necessidades. Tecnicamente, a inteligência de marketing está inserida em um dos quadrantes que fazem parte do (SISTEMA DE INFORMAÇÕES DE MARKETING - SIM, sistema analítico; pesquisa de marketing; inteligência de marketing e registros internos) (CALOF; WRIGHT, 2008; LAURINDO; MACUL, 2014; MILENA; PALACIOS, 2013; QUEIROZ, 2010; TOLEDO; MORAES; ZILBER, 2010; ZAPATA MENDIVELSO, 2015). 
O sistema de informação de marketing tem como finalidade abastecer a demanda por informações provindas dos gestores, transformando e filtrando dados em informações úteis à empresa (COZMIUC; PETRISOR, 2018; GENADINIK, 2017; KOTLER; KARTAJAYA; SETIAWAN, 2011). É um processo complexo de interação entre pessoas, máquinas e procedimentos destinados a gerar um fluxo sistemático e contínuo de dados, coletados de fontes internas e externas à empresa, para serem usados como base para a tomada de decisão em áreas estratégicas específicas de marketing (CALOF; WRIGHT, 2008; LAURINDO; MACUL, 2014; MILENA; PALACIOS, 2013; QUEIROZ, 2010; TOLEDO; MORAES; ZILBER, 2010; ZAPATA MENDIVELSO, 2015). Conhecimento acaba por propiciar as ações de marketing.

O conhecimento é um dos bens mais preciosos de uma empresa, sendo necessário compreender mais profundamente o que é conhecimento. Aceitar apenas a definição da palavra não basta, é preciso contextualizar com a empresa, uma vez que o conhecimento se diferencia de informação por sua finalidade (ANDERL; ANOKHIN; ARNDT, 2018; STARK; DAMERAU; LINDOW, 2018). Ambos consistem em declarações verídicas, porém, no conhecimento, identifica-se um propósito ou uma função, que, nesse caso, deverá sempre fazer alusão aos interesses da organização, sendo o conhecimento a informação mais valiosa de uma empresa e, como consequência, mais difícil de ser gerenciada. É valiosa porque alguém deu à informação um contexto, um significado, uma interpretação; alguém refletiu sobre o conhecimento e agregou a ele sua própria sabedoria, considerou suas implicações mais amplas (COHEN, 2011; OZKAYA et al., 2015).

A empresa precisa, invariavelmente, manter-se sustentada de novos conhecimentos, e, para isso, precisa ter a habilidade de converter os dados e as informações em novas fontes geradoras de conhecimento (CALOF; WRIGHT, 2008; LAURINDO; MACUL, 2014; MILENA; PALACIOS, 2013; QUEIROZ, 2010; TOLEDO; MORAES; ZILBER, 2010; ZAPATA MENDIVELSO, 2015).

As organizações já identificam a informação e o conhecimento como uma grande vantagem competitiva. Nesse sentido, remete-se a inteligên- cia competitiva, tema a ser abordado em futuros estudos. Portanto, também compete ao marketing dar suporte e abastecer os gestores desse conhecimento, proporcionando condições para adquirir e gerenciar essas informações (CALOF; WRIGHT, 2008; LAURINDO; MACUL, 2014; MILENA; PALACIOS, 2013; QUEIROZ, 2010; TOLEDO; MORAES; ZILBER, 2010; ZAPATA MENDIVELSO, 2015).

Compreende-se, portanto, que as organizações apresentam, em sua maioria, necessidades de informações singulares; por isso, cada sistema deverá estar adaptado, exclusivamente, a cada modelo de gestão. É evidente que um dos papéis dos gestores é traçar os rumos da empresa, e a Inteligência de Marketing é, justamente, o facilitador para controlar, agilizar, coordenar e ajudar esse processo de tomada de decisões. Uma empresa, ao colher dados, deverá tomar o máximo de cuidado, pois a qualidade de uma decisão depende da quantidade de informações que está disponível no momento em que ela é tomada. Esse volume de informações é decisivo, pois, para os gestores, isso significa expansão ou restrição de seu campo de alternativas (CALOF; WRIGHT, 2008; LAURINDO; MACUL, 2014; MILENA; PALACIOS, 2013; QUEIROZ, 2010; TOLEDO; MORAES; ZILBER, 2010; ZAPATA MENDIVELSO, 2015).

\section{PROCEDIMENTOS METODOLÓGICOS}

O papel da metodologia da pesquisa é guiar o processo da pesquisa por meio de um sistema de procedimentos. Um método é um conjunto de processos pelos quais se torna possível estudar uma determinada realidade (DEMO, 1995; LAKATOS; MARCONI, 2010; RAMPAZZO, 2005). Caracteriza-se, ainda, pela escolha de procedimentos sistemáticos para descrição e explicação de uma determinada situação sob o estudo.

Este estudo utiliza um delineamento exploratório e uma abordagem qualitativa. Optou-se por utilizar o método de estudo de caso, entre outros métodos de pesquisa qualitativa, por se adequar à questão proposta para a pesquisa de campo e pela possibilidade de se observar semelhanças e diferenças entre a unidade de análise e o que foi discu- 
tido na literatura (GEHMAN et al., 2017; ŠALKOVSKA; OGSTA, 2014; YIN, 2015). Um estudo de caso é um método de pesquisa que é usado para gerar uma compreensão profunda e multifacetada de uma questão complexa em seu contexto da vida real. É um projeto de pesquisa estabelecido, usado, extensivamente, em uma ampla variedade de disciplinas, particularmente em ciências sociais (BAXTER; JACK, 2008; CROWE et al., 2011; HARRISON et al., 2017), para explicar, descrever ou explorar eventos ou fenômenos nos contextos cotidianos em que ocorrem (YIN, 2015).

$\mathrm{O}$ estudo de caso foi realizado na organização HBSA, cuja unidade de análise foram as atividades da empresa investigada, relacionadas à inteligência de marketing. As fontes de evidência foram entrevistas em profundidade, documentos internos e aqueles disponíveis no ambiente digital e observação direta. Foram entrevistados três gestores (foram gravadas e transcritas): colaborador "1", vice-presidente de operações, 53 anos de idade e 16 anos de empresa; colaborador "2", gerente comercial, 42 anos, há 1 ano na empresa e; colaborador " 3 " da área de planejamento, 46 anos e 8 anos de empresa. As evidências foram coletadas no segundo semestre de 2017. As etapas preparatórias de coleta de evidências na organização e posterior análise seguiram um protocolo pré-estabelecido de acordo com os modelos de Toledo e Shiraishi, (2009) e Yin (2015). Para encontrar padrões ao cruzar todos os dados obtidos na pesquisa de campo, foi utilizada a estratégia proposta por Eisenhardt (1989), de definir categorias (dimensões), baseadas na questão de pesquisa e literatura que compôs o referencial teórico. Seguiu-se, então, a classificação dos excertos das entrevistas de acordo com as categorias previamente definidas e das demais evidências obtidas a fim de preservar para a análise e a consideração apenas os elementos que, de alguma forma, estivessem ligados às categorias definidas. A etapa de análise dos dados obtidos foi realizada por meio da triangulação dos dados e do referencial teórico.

\section{O CASO HBSA}

A empresa Hidrovias do Brasil oferece soluções logísticas de alta qualidade para o transporte de commodities agrícolas, minérios, produtos siderúrgicos e outras cargas, com projetos customizados e de longo prazo, atuando em toda a América Latina. Nascida a partir de uma startup e fundada em 2010, a Hidrovias do Brasil S.A. é uma empresa que desenvolve soluções logísticas integradas na América Latina com foco no aproveitamento do transporte hidroviário, por meio de projetos inovadores e competitivos (HBSA, 2018).

Constituída pelo fundo de infraestrutura do Pátria Investimentos, a Hidrovias do Brasil conta, ainda, com a participação de outros fundos, como o canadense AIMCO, o Temasek, fundo soberano de Cingapura, o IFC - braço financeiro do Banco Mundial, e o BNDESPar, gestor de participações em empresas detidas pelo BNDES, entre outros sócios também representados pelo Pátria Infraestrutura. Desenvolvendo projetos customizados em toda a América Latina, a atuação da companhia abrange, atualmente, duas operações principais: Corredor Logístico Sul e Corredor Logístico Norte. A Operação Norte foi criada para atender a uma importante demanda de transporte e escoamento de grãos da região Centro-Oeste pelo Arco Norte do Brasil, estabelecendo uma nova rota, que aproveita o potencial hidroviário do país para movimentar cargas e gerar desenvolvimento e competitividade para a região e o agronegócio, além de contribuir, de forma expressiva, para a balança comercial brasileira (HBSA, 2018)

A Operação Sul foi o primeiro projeto logístico da Hidrovias do Brasil, tendo seu início com a contratação junto à Vale para o escoamento da produção de minério da região de Corumbá (MS) com destino a San Nicolas, na Argentina, contribuindo com o desenvolvimento da região Centro-Oeste do país. Com a implantação do projeto Vale, ocorreram avanços operacionais significativos que levaram à ampliação do negócio, agregando novos contratos que trouxeram a diversificação da Operação Sul, como o Projeto Grãos Sul, para transporte de grãos e fertilizantes, o Projeto Limday, para transporte de celulose, e o Projeto TGM, um terminal no Porto de Montevideo para movimentação de grãos, cavaco de madeira e fertilizantes (HBSA, 2018). 


\subsection{CARACTERIZAÇÃO DO SETOR}

O setor de logística está relacionado com a maneira como as empresas organizam suas cadeias de suprimentos e a capacidade dos operadores e intermediários logísticos que delas dependem. Corresponde, assim, a um enfoque microeconômico que influencia sobremaneira a competitividade da região (POMPERMAYER; CAMPOS NETO; PAULA, 2017).

Embora a administração pública não atue diretamente nas atividades desse bloco, deve buscar promover o desenvolvimento de melhorias das atividades logísticas do setor privado, pois dele depende o uso eficiente dos recursos de infraestrutura, bem como a maior facilidade na adoção de novos procedimentos definidos pelo Poder Público. $\mathrm{O}$ papel das pequenas e médias empresas (PMEs) merece destaque neste bloco, pois seu desempenho logístico é inferior àquele das grandes empresas, ao mesmo tempo em que tem uma grande importância na geração de empregos. A competitividade das PMEs deve ser de interesse do Governo e das entidades locais. Organismos como SEBRAE, Federações de Indústrias e outros órgãos de classe têm investido na capacitação na área de gestão Logística. Como exemplo dessas ações, pode-se citar o Programa IEL de Desenvolvimento e Qualificação de Fornecedores (POMPERMAYER; CAMPOS NETO; PAULA, 2017).

O programa, desenvolvido a partir de experiências bem-sucedidas nos estados de Goiás, Espírito Santo, Bahia e Maranhão, já foi implantado em mais de 15 estados. O programa procura desenvolver fornecedores (de micro, pequeno e médio porte) de grandes empresas locais, chamadas de empresas-âncora - como Alcoa, Petrobrás, Nova Schin, Oi, Bosch, Vale, Gerdau, Garoto, Perdigão - entre outras de modo a aumentar as vendas dos pequenos e garantir a qualidade das compras dos grandes. Essas iniciativas têm obtido resultados positivos relacionados ao desempenho da logística das empresas (POMPERMAYER; CAMPOS NETO; PAULA, 2017).

Os operadores logísticos também vêm ganhando importância no contexto nacional e internacional, ao agirem como facilitadores da cadeia de suprimentos e aumentarem a competitividade das empresas que as compõem, por meio da obtenção de economias de escala na realização das atividades logísticas das empresas.

Ao considerar uma abordagem sistêmica e os objetivos de melhoria da cadeia de suprimentos, não se pode desprezar o desempenho das empresas e a forma como elas se organizam nas cadeias de suprimentos. Ações que promovem a melhoria da logística empresarial, ou seja, melhorias no nível microeconômico terão impacto significativo sobre o desempenho da logística e transporte na região, assim como sobre o uso eficiente da infraestrutura disponível (POMPERMAYER; CAMPOS NETO; PAULA, 2017).

\subsubsection{Logística Hidroviária}

O transporte aquaviário é apontado como o meio de transporte mais barato e o que menos consome energia. Também é considerado o mais indicado para mover grandes volumes a grandes distâncias. O Brasil, além de sua extensa costa marítima, tem, em seu território, diversos rios caudalosos, propícios à navegação; entretanto, esse não é o meio mais utilizado no país para a movimentação interna de cargas (OLSSON; SANTÂNGELO, 2018; GONÇALVES, F.; VIEIRA; GONÇALVES, R., 2018; SILVEIRA, 2018; POMPERMAYER; CAMPOS NETO; PAULA, 2017).

Os vários rios do Brasil, frequentemente caudalosos, sempre foram vistos como uma forma de barateamento dos transportes, mas também constituíam um obstáculo a ser vencido, pois nem sempre eram navegáveis, por possuírem muitas cachoeiras (OLSSON; SANTÂNGELO, 2018; GONÇALVES, F.; VIEIRA; GONÇALVES, R., 2018; SILVEIRA, 2018; POMPERMAYER; CAMPOS NETO; PAULA, 2017).

$\mathrm{O}$ transporte aquaviário, incluindo o marítimo e o hidroviário interior, é, geralmente, apontado como o meio mais eficiente e de menor custo. De fato, o consumo de combustível e o custo associado aos veículos são, em geral, menores que nos modos terrestre (rodoviário e ferroviário) e aéreo. Essas características são mais importantes para o transporte de produtos de baixo valor agre- 
gado que envolve grandes volumes, uma vez que, nesse caso, o transporte representa uma porcentagem significativa do valor comercializado. Isso contrasta com os produtos de alto valor agregado, caso em que o tempo passa a ter maior relevância. Além disso, o transporte pelas águas costuma se valer de vias naturais preexistentes, o que reduz o custo associado à implantação das vias, que é alto em ferrovias e rodovias. O transporte aéreo também não depende da implantação de uma pesada infraestrutura viária, mas, para isso, depende de veículos de alto custo e elevado consumo de combustível, o que não ocorre no transporte aquaviário (OLSSON; SANTÂNGELO, 2018; GONÇALVES, F.; VIEIRA; GONÇALVES, R., 2018; SILVEIRA, 2018; POMPERMAYER; CAMPOS NETO; PAULA, 2017).

Entretanto, o transporte aquaviário moderno depende, cada vez mais, de instalações de transbordo sofisticadas, que envolvem custos elevados referentes a portos e terminais. Isso implica menor adequação desse modo de transporte para deslocamentos curtos, para os quais o transporte rodoviário, mais versátil e menos dependente de instalações de transbordo, é o mais indicado. Além de depender de instalações de transbordo e acesso rodoviário, o transporte hidroviário interior, foco deste estudo, está sujeito às restrições à navegabilidade em rios, lagos e canais, em geral, inexistentes no transporte marítimo (OLSSON; SANTÂNGELO, 2018; GONÇALVES, F.; VIEIRA; GONÇALVES, R., 2018; SILVEIRA, 2018; POMPERMAYER; CAMPOS NETO; PAULA, 2017).

\subsection{ANÁLISE E DISCUSSÃO DO CASO}

Inteligência competitiva é uma forma proativa de captar e organizar informações relevantes sobre o comportamento da concorrência, mas também dos clientes e do mercado como um todo (TOLEDO; MORAES; ZILBER, 2010; ZAPATA MENDIVELSO, 2015). A inteligência competitiva colabora com a análise das tendências e dos cenários, permitindo um melhor processo de tomada de decisão em curto e longo prazo (TOLEDO; MORAES; ZILBER, 2010; ZAPATA MENDIVELSO, 2015).
No universo corporativo, conhecer os contextos em que o país e o mundo se encontram é essencial para as estratégias de negócio. A má interpretação ou o desconhecimento dessas circunstâncias pode levar a decisões equivocadas (CAMPOMAR; MOTTA, 2007). Por isso, transformar dados dispersos em um diferencial competitivo pode contribuir para a construção de um planejamento. A inteligência das empresas consiste, principalmente, na acumulação e na interpretação de conhecimentos variados. É uma das principais abordagens aplicadas dentro de uma organização, adotada por aquelas que desejam melhorar a capacidade de saber o que acontece no seu entorno. Teoricamente, quem atua com essa prática consegue realizar a coleta e a análise de informações do ambiente externo com a proposta de apoiar as decisões estratégicas da empresa, prevenindo surpresas e favorecendo a previsão de tendências (MADEIRA; TOLEDO; SILVEIRA, 2015; ROD et al., 2016).

Ao longo dos anos, por meio da utilização da inteligência marketing, a empresa Hidrovias do Brasil utiliza-se da ideia de valor compartilhado, que pode ser definido como políticas e práticas operacionais que aumentam a competitividade da empresa, e, ao mesmo tempo, melhoram as condições socioeconômicas nas comunidades em que a empresa atua.

Observa-se que um dos objetivos da HBSA é se aproveitar do desenvolvimento provido na região para se autobeneficiar, seja contribuindo para futuros colaboradores capacitados seja se aproveitando da infraestrutura proporcionada. Seguindo a evolução de mercado, a empresa foi capaz de estabelecer novas rotas hidroviárias em uma região pouco explorada anteriormente.

Com a Operação Norte, a empresa foi capaz de viabilizar uma região altamente estratégica no que diz respeito ao escoamento de grãos. Dessa maneira, possibilitou que outras empresas do ramo usufruíssem de toda a estrutura gerada no local. Com essas medidas, a HBSA consegue atingir mercados inexplorados por seus concorrentes, agregando ainda mais valor à sua marca, buscando consolidar-se entre as principais empresas do segmento.

A localização estratégica da Operação Norte 
possibilita atenuar o movimento dos portos de outras regiões brasileiras, contribuindo diretamente para a redução do tráfego de caminhões, do custo logístico e do tempo necessário para escoar a produção para os principais mercados do agronegócio brasileiro.

Utilizando-se da alta tecnologia, a HBSA busca ter controle de todos os processos e oportunidades disponíveis no mercado, monitorando $24 \mathrm{~h}$ todas as rotas disponíveis e lugares não explorados a fim de localizar pontos novos de investimento.

O Quadro 1 traz uma síntese das principais informações coletadas no transcorrer da pesquisa, elencados por temas relevantes ao problema de pesquisa deste trabalho.

Quadro 1 - Tabulação das respostas

\begin{tabular}{|c|c|c|c|}
\hline $\begin{array}{c}\text { TEMA } \\
\text { CENTRAL }\end{array}$ & APURADO & LITERATURA & AUTORES \\
\hline $\begin{array}{l}\text { Marketing } \\
\text { estratégico }\end{array}$ & \begin{tabular}{|l|} 
O uso da segmentação de \\
mercado permite a empresa \\
entender seu público geral, \\
que, por meio da escolha do \\
mercado alvo, acaba por facilitar \\
a escolha da melhor estratégia de \\
posicionamento no mercado. \\
A empresa busca ser o \\
melhor operador logístico na \\
América Latina, com foco no \\
aproveitamento do transporte \\
hidroviário, por meio de projetos \\
inovadores e competitivos. \\
Os segmentos são focados \\
no Corredor Logístico Sul e \\
Corredor Logístico Norte. \\
A empresa visa fornecer serviços \\
com o mais alto padrão em \\
sustentabilidade, qualidade, \\
prazo e custo logístico, alinhados \\
às necessidades e com a \\
satisfação do cliente.
\end{tabular} & $\begin{array}{l}\text { “Um segmento de mercado consiste } \\
\text { em um grande grupo que é identificado } \\
\text { a partir de suas preferências, poder } \\
\text { de compra, localização geográfica, } \\
\text { atitudes de compra e hábitos de } \\
\text { compra similares. Segmentação de } \\
\text { marketing é um esforço para aumentar } \\
\text { a precisão do marketing da empresa" } \\
\text { "Uma vez que a unidade de negócios } \\
\text { tenha selecionado o valor, passa-se } \\
\text { para a segunda etapa, a da entrega } \\
\text { de valor. As especificações tangíveis } \\
\text { do produto e dos serviços devem } \\
\text { ser detalhadas; um preço-alvo } \\
\text { deve ser estabelecido; o produto } \\
\text { deve ser fabricado e distribuído. } \\
\text { O desenvolvimento dos atributos } \\
\text { específicos, dos preços e da } \\
\text { distribuição acontece nessa etapa e é } \\
\text { parte do marketing." }\end{array}$ & $\begin{array}{l}\text { (AAKER; MCLOUGH- } \\
\text { LIN, 2010; BEEMER; } \\
\text { SHOOK, 1998; KERIN; } \\
\text { PETERSON, 2009; } \\
\text { ZENONE, 2007). }\end{array}$ \\
\hline $\begin{array}{l}\text { Sistema de } \\
\text { Inteligência } \\
\text { de Marke- } \\
\text { ting }\end{array}$ & \begin{tabular}{|l|} 
Em 2016, por meio da \\
inteligência competitiva, \\
verificou que o investimento \\
nessa rota já geraria \\
desenvolvimento para região e \\
futuro mercado para a empresa. \\
Por meio de um sistema \\
moderno de satélites, base \\
de dados e inteligência nos \\
sistemas hidroviários, existe \\
um monitoramento de 24 horas \\
sobre o transporte nas vias, e \\
um grande armazenamento de \\
informações.
\end{tabular} & \begin{tabular}{|l|} 
"Os profissionais de marketing fazem \\
uso da inteligência competitiva para \\
colherem informações do mercado, \\
transformar dados em conhecimentos \\
e desta forma conceber as melhores \\
estratégias para a manutenção ou \\
conquista de mercados novos ou já \\
explorados.” \\
"Sistema de Inteligência de Marketing \\
é um conjunto de procedimentos e \\
fontes, usado por administradores \\
para obter informações diárias sobre \\
os desenvolvimentos pertinentes no \\
ambiente de marketing."
\end{tabular} & $\begin{array}{l}\text { (CALOF; WRIGHT, } \\
\text { 2008; LAURINDO; } \\
\text { MACUL, 2014; MI- } \\
\text { LENA; PALACIOS, } \\
\text { 2013; QUEIROZ, 2010; } \\
\text { TOLEDO; MORAES; } \\
\text { ZILBER, 2010; ZAPA- } \\
\text { TA MENDIVELSO, } \\
\text { 2015). } \\
\text { (ANDERL; ANOKH- } \\
\text { IN; ARNDT, 2018; } \\
\text { CALOF; ARCOS; } \\
\text { SEWDASS, 2018; } \\
\text { NEWSWIRE; YORK, } \\
\text { 2013) }\end{array}$ \\
\hline
\end{tabular}

Fonte: os autores (2018). 


\section{CONSIDERAÇÕES FINAIS}

O objetivo deste trabalho foi entender a inteligência marketing em uma empresa que desenvolve soluções logísticas integradas. Para tanto, foi realizada uma pesquisa qualitativa exploratória embasada no método estudo de caso. A análise foi concluída com êxito, permitindo o entendimento de como é tratada a inteligência de marketing na empresa.

Observa-se que não existe um setor formalizado de inteligência de marketing, nem mesmo um departamento no qual fica concentrada a responsabilidade. Porém, se existir, em diversas áreas, a busca por informações de mercado, as análises de cenários e a busca por oportunidades ocorrem de forma orgânica, constituindo uma inteligência de marketing não reconhecida como tal na empresa que estuda.

A inteligência de marketing apresenta-se como instrumento identificador de oportunidades a serem trabalhadas pelos gestores. Cada vez mais, as ações inerentes ao marketing têm-se transformado mais em uma disputa pela propriedade da informação do que pela propriedade de outros recursos, podendo-se copiar os maquinários, os produtos e os processos dos seus concorrentes, mas não suas informações e seu conhecimento. As informações adquiridas por uma empresa são ou podem ser sua principal vantagem competitiva.

Desse modo, a Inteligência de marketing se mostra fundamental na empresa estudada, abrangendo diversos níveis de decisões em vários pontos. A escolha de algum produto ou serviço está atrelada ao marketing, à percepção da empresa $\mathrm{e}$ ao público. Por isso, as ações de Marketing sempre devem estar alinhadas à percepção do público-alvo e clientes e ao objetivo da empresa. Para tanto, as informações necessárias para esse alinhamento são fornecidas pela Inteligência de marketing.

Mesmo conseguindo diversas informações por meio de profissionais da área, como todo trabalho científico, existirão limitações no que diz respeito ao fornecimento de dados, devido ao sigilo de grande parte das informações. Outra dificuldade encontrada foi a falta de tempo disponível dos entrevistados, o que acarretou em um menor percentual de informações coletadas.
Em continuidade, é recomendável aos futuros pesquisadores que realizam a mesma pesquisa, utilizando-se de métodos quantitativos e/ou qualitativos em períodos diferentes do apresentado. Sugere-se, ainda, que se façam estudos múltiplos de casos, estudando empresas que usam ou não o sistema de informação de marketing, cruzando as informações adquiridas.

\section{REFERÊNCIAS}

AAKER, D. A.; MCLOUGHLIN, D. Strategic market management: global perspectives. UK: John Wiley \& Sons, 2010.

AMERICAN MARKETING ASSOCIATION. What is content intelligence. Disponível em: https://www.ama.org/partners/content/Pages/ what-is-content-intelligence.aspx. Acesso em: 10 dez. 2018.

ANDERL, R.; ANOKHIN, O.; ARNDT, A. Efficient factory 4.0 Darmstadt: industrie 4.0 implementation for midsize industry. In: SENDLER, Ulrich (ed.). The Internet of Things: industrie 4.0 unleashed. [S.l: s.n.], 2018. p. 117-129.

BARBOSA, Conceição Aparecida Pereira; TOLEDO, Luciano Augusto; ZILBER, Moises Ari. Competitive advantages alliances under the web usage. Int. J. Internet and Enterprise Management, v. 8, n. 4, p. 316-333, 2016.

BAXTER, P.; JACK, S. Qualitative case study methodology: study design and implementation for novice researchers. The Qualitative Report, v. 13, n. 4, p. 544-559, 2008.

BEEMER, C. B.; SHOOK R. L. Marketing estratégico: tudo o que mega e microempresários devem saber para conquitar novos clientes. São Paulo: Futura, 1998.

CALOF, J. L.; WRIGHT, S. Competitive intelligence: A practitioner, academic and interdisciplinary perspective. European Journal of Marketing, v. 42, n. 7/8, p. 717-730, 2008. 
CALOF, J.; ARCOS, R.; SEWDASS, N. Competitive intelligence practices of European firms. Technology Analysis and Strategic Management, v. 30, n. 6, p. 658-671, 2018.

CAMPOMAR, M. C.; MOTTA, K. D. O sistema de informações no planejamento de marketing: em busca de vantagem competitiva. Revista de Gestão da Tecnologia e Sistemas de Informação, v. 4, n. 1, p. 23-46, 2007.

COHEN, E. Anthropology of Knowledge. In: MARCHAND, T. (ed.). Making Knowledge: explorations of the indissoluble relation between mind, body and environment. [S.l.] : WileyBlackwell, 2011. p. 183-192.

COZMIUC, D.; PETRISOR, I. Industrie 4.0 by siemens: steps made today. Journal of Cases on Information Technology, v. 20, n. 2, p. 30-48, 2018.

CROWE, S. et al. The case study approach. BMC Medical Research Methodology, v. 11, p. 1-9, 2011.

DEMO, P. Metodologia científica em Ciências Sociais. São Paulo: Atlas, 1995.

EISENHARDT, K. M. Building theories from case study research. Academy of Management Review, v .14, n .4, p. 532-550, 1989.

FLYNN, B.; HUO, B.; ZHAO, X. The impact of supply chain integration on firm performance: The moderating role of competitive strategy. Supply Chain Management: An International Journal, v. 19, n. 4, p. 1, 2014.

GEHMAN, J. et al. Finding theory-method fit: a comparison of three qualitative approaches to theory building. Journal of Management Inquiry, v. 27, n. 3, p. 1-18, May 2017.

GENADINIK, A. Marketing strategy to reach 1,000,000! SEO; social media | Udemy. 2017. Disponível em: hhttps://www.udemy. com/marketing-plan-strategy-become-a-greatmarketer/. Acesso em: 10 dez. 2018.
GONÇALVES, F. S.; VIEIRA, G. B. B.; GONÇALVES, R. B. Tecnologias de informação aplicadas à logística internacional. Revista Gestão Industrial, v. 14, n. 3, p. 129-150, 2018.

GUMMESSON, E. Commentary on the role of innovation in driving the economy: lessons from the global financial crisis. Journal of Business Research, v. 67, n. 1, p. 2743-2750, 2014.

GUNASEKARAN, A. Information systems in supply chain integration and management. European Journal of Operational Research, v. 159, n. 2, p. 269-295, Dec. 2004.

HARRISON, H. et al. Case study research: foundations and methodological orientations. FQS Forum Qualitative Sozialforschung, v. 18, n. 1, 2017. Disponível em: http://www.qualitativeresearch.net/index.php/fqs/article/view/2655. Acesso em: 10 dez. 2018.

HBSA. Projetos Logísticos. 2018. Disponível em: http://hbsa.com.br/projetos-logisticos. Acesso em: 10 dez. 2018.

KERIN, R. A.; PETERSON, R. A. Problemas de marketing estratégico: comentários e casos selecionados. 11. ed. Porto Alegre: Bookman, 2009.

KOTLER, P.; KARTAJAYA, H.; SETIAWAN, I. Marketing 3.0: from products to customers to the human spirit. US: John Wiley \& Sons, 2011.

KOTLER, P.; KELLER, K. L. Administração de marketing. 12. ed. São Paulo: Pearson Prentice Hall, 2011.

LAKATOS, E. M; MARCONI, M. A. Fundamentos de metodologia científica. São Paulo: Atlas, 2010.

LAMBIN, J. J. Marketing estratégico. Porto Alegre: Bookman, 2002.

LAURINDO, F. J. B.; MACUL, L. G. S. Inteligência competitiva no marketing digital. 
In: CONGRESSO INTERNACIONAL DE GESTÃO DA TECNOLOGIA E SISTEMAS DE INFORMAÇÃO - CONTECSI, 11., 2014, São Paulo. Anais [...]. São Paulo: TECSI/EAC/FEA/ USP, 2014.

MADEIRA, A. B; TOLEDO, L. A; SILVEIRA, J. A. G. da. Marketing segmentation : your role for diversity in dynamical systems segmentação de mercado: seu papel para a diversidade em sistemas dinâmicos. Revista Gestão Org., v. 13, n. 1, p. 7178,2015 .

MilenA, C. G. A.; PAlACIOS, A. L. G. La inteligencia de mercado: una estrategia hacia la competitividad. Revista Ensayos: Revista de los estudiantes de Administración de Empresas, v. 6, n. 6, p. 157-167, 13 nov. 2013. Disponível em: https://revistas.unal.edu.co/index.php/ensayos/ article/view/49810 Acesso em: 10 dez. 2018.

NEWSWIRE, P. R.; YORK, New. Global Business Intelligence Market Report (2013 2018). PR Newswire, [S.l.], 2013. Disponivél em: $\quad$ https://www.prnewswire.com/newsreleases/global-business-intelligence-marketreport-2013---2018-237338771.html. Acesso em: 10 dez. 2018.

OLSSON, E.; SANTÂNGELO, C. C. F. Logística empresarial: Análise do processo de entregas da empresa Neto Comércio e Transporte de Material de Construção Ltda-ME. Anais da Semana Científica e de Extensão do Centro de Ciências Sociais Aplicadas-Gestão, v. 4, n. 1, 2018.

OZKAYA, H. E. et al. Market orientation, knowledge competence, and innovation. International Journal of Research in Marketing, v. 32, p. 309-318, 2015.

POMPERMAYER F. M.; CAMPOS NETO, C. A. S.; PAULA J. M. P. Hidrovias no Brasil: perspectiva histórica, custos e institucionalidade. Instituto de Pesquisa Econômica Aplicada - IPEA, v. 53, n. 9, p. 1-58, 2017.
PRAJOGO, D. et al. The relationships between information management, process management and operational performance: internal and external contexts. International Journal of Production Economics, v. 199, p. 95-103, May 2018.

QUEIROZ, J. P. de. Análise do uso de sistema de informações de marketing e de suas contribuições para a gestão de marketing de empresas varejistas. In: ENCONTRO DA ANPAD, 34., 2010, São Paulo. Anais [...]. São Paulo: ANPAD, 2010.

RAMPAZZO, L. Metodologia Científica para alunos dos cursos de graduação e pósgraduação. 3. ed. São Paulo: Loyola, 2005.

ŠALKOVSKA， J.; OGSTA， E. Quantitative and qualitative measurement methods of companies' marketing efficiency. Management of Organizations: Systematic Research, n. 70, p. 91-105, 2014.

SILVEIRA, M. R. Transportes e a logística frente à reestruturação econômica no Brasil. Mercator, v. 17, p. 1-20, 2018.

STARK, R.; DAMERAU, T.; LINDOW, K. Industrie 4.0: digital redesign of product creation and production in Berlin as an industrial location: challenges and solutions for digital transformation and innovation. In: SENDLER, Ulrich (ed.). The Internet of Things: industrie 4.0 unleashed. [S.l: s.n.], 2018. p. 171-188.

TOLEDO, L. A.; MORAES, C. A. de; ZILBER, M. A. SIC - Sistema de Inteligência Competitiva: um estudo descritivo exploratório em uma empresa do setor brasileiro de comunicações. PRISMA. COM, v. 9, p. 1-30, 2010.

TOLEDO, L. A.; SHIRAISHI G. Estudo de caso em Pesquisas exploratórias qualitativas: Um ensaio para a proposta de protocolo do estudo de caso. Revista da FAE, v. 12 n. 1, p. 103-120, 2009. 
VALDÉS, J Á. Marketing estratégico e estratégia competitiva de empresas turísticas. 2003. 321 f. Tese (Doutorado em Administração) Universidade de São Paulo, São Paulo, 2003.

WAGNER, S. M.; EGGERT, A. Co-management of purchasing and marketing: why, when and how? Industrial Marketing Management, v. 52, p. 27 36, 2016.

YIN, R. K. Estudo de caso: planejamento e métodos [case study: planning and methods]. 5 ed. Porto Alegre: Bookman, 2015.

ZAPATA MENDIVELSO, Gloria Patricia Gerencia. Business intelligence to support decision-making of the company. 2015.

Disponível em: http://repository.unimilitar.edu.co/ handle/10654/12502. Acesso em: 20 ago. 2018.

ZENONE, L. C. Marketing estratégico e competitivo empresarial formulado estratégias mercadológicas para organizações de desempenho. São Paulo: Novatec Editora, 2007. 